Examining the role of social network size and structural holes

Singh, Robert P;Hybels, Ralph C;Hills, Gerald E

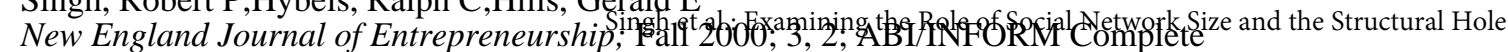
pg. 47

\title{
Examining the Role of Social Network Size and Structural Holes
}

\author{
Robert P. Singh \\ Ralph C. Hybels \\ Gerald E. Hills
}

This study examines the importance of social network size and structural holes within the network to the entrepreneurial opportunity recognition process. Four hypotheses are tested using data collected from 256 information technology consulting entrepreneurs. Regression analysis found that network size and number of structural holes within an entrepreneur's network were significantly and positively related to the number of new venture ideas identified and opportunities recognized. Implications for future research and practice are discussed.

$\mathbf{T}$ he fundamental activity of entrepreneurship is new venture creation (Gartner 1985 and 1990), and a major step in any entrepreneurial venture creation process is the recognition of the opportunity by the entrepreneur (Timmons et al. 1987). Christensen, Madsen, and Peterson (1989) define opportunity recognition as perceiving a possibility for new profit potential through (1) the founding and formation of a new venture, or (2) the significant improvement of an existing venture. From this broad definition, opportunity recognition can be conceived of as an activity that can occur both prior to firm founding and after firm founding throughout the life of the firm. Yet, as Hills (1995) points out, unlike opportunity evaluation, opportunity recognition has received little attention in the academic literature.

Most people have contact, frequent or sporadic, with a great many people (Burt 1986; Pool and Kochen 1978), and an individual's personal social network consists of all the people that the individual knows both well and not so well (Barnes 1972; Mitchell 1969). Entrepreneurs' personal social networks have been called the "most significant resource of the firm" (Johannisson 1990) and social encounters between an entrepreneur and his or her network contacts are often a source of new venture ideas (Christensen and Peterson 1990). This can be attributed to the fact that no person has perfect information with which to make choices and decisions. Individuals experience what Simon (1976) labels "bounded rationality" because they are limited in their ability to process and store information. An entrepreneur's social network may help to expand the boundaries of rationality by offering access to knowledge and information not possessed by the individual entrepreneur, thus exposing the entrepreneur to new venture ideas and opportunities.
Aldrich, Rosen, and Woodward (1987) and Hansen (1995) found that size and interconnectivity of an entrepreneur's network significantly affect new firm performance. Zhao and Aram (1995) reported that entrepreneurs in higher growth technology firms had greater range and intensity of business networking than did those in lower growth technology firms. However, there is scant empirical exploration of the impact of social networks on opportunity recognition. In one earlier study, Hills, Lumpkin, and Singh (1997) reported that entrepreneurs who used social network sources to learn of entrepreneurial opportunities (labeled "network entrepreneurs") recognized significantly more opportunities than those who recognized the opportunities for their firms individually ("solo entrepreneurs"). They reported significant differences between solo and network entrepreneurs on a number of factors; however, the measure of solo entrepreneurs versus network entrepreneurs was based on a single questionnaire item and the authors called for further testing and the use of multi-item measures.

Studying characteristics of entrepreneurs' social networks may help to shed light on the new venture creation process. This article builds on the exploratory findings of Hills et al. (1997) by examining the importance of network size and structural holes (Burt 1992) within the network to the opportunity recognition process. Based on prior research, this article provides a conceptual discussion of the entrepreneurial opportunity recognition process that distinguishes identifying new venture ideas from recognizing opportunities (Singh 2000; Singh et al. 1999) Then, using survey data from 256 entrepreneurs, the authors develop and test four hypotheses and discuss implications and future research needs.

\section{New Venture Ideas v. New Venture Opportunities}

An idea for an entrepreneurial venture does not necessarily equate to an opportunity - although it is always at the heart of an opportunity (Bygrave 1994; Timmons 1990 and 1994). Entrepreneurship is a market-driven process, and as Timmons (1990) points out, "building a better mousetrap" will not necessarily mean that people will want to buy the new trap. Other factors must exist to support the new product idea for it to become an opportunity as potential cus- 
tomers must want the product. Hence, we can think of the "idea" as a stepping stone that leads to an opportunity.

This study utilizes the basic model of opportunity recognition developed by Singh (2000). The model is illustrated in Exhibit 1. In earlier research, Singh (2000) and his associates (Singh et al. 1999) reported strong support for the validity of the model as more than 86 percent of the entrepreneurs queried accepted the model as a valid depiction of the opportunity recognition process. Thus, this study distinguishes new venture ideas from opportunities. More specifically, idea identification must take place before an opportunity to be recognized, and the hypotheses developed in the following section distinguish between ideas and opportunities. nized, screened and assessed, and then, if appropriate, acted upon. However, relatively little empirical research has examined the role of social networks to opportunity recognition.

Koller (1988) studied the sources of new venture ideas. He surveyed 65 entrepreneurs in several industries and found that half reported the ideas for their firms had come through social contacts; the other half had recognized the ideas for their businesses individually. In their study, Hills et al. (1997) found a similar split in the number of entrepreneurs who used social contacts to recognize opportunities and found significant differences between "solo entrepreneurs" (those who recognized the idea for their business themselves) and "network entrepreneurs" (those who recognized the idea for their business through social contacts)

\section{Exhibit 1}

\section{Basic Steps of the Opportunity Recognition Process}

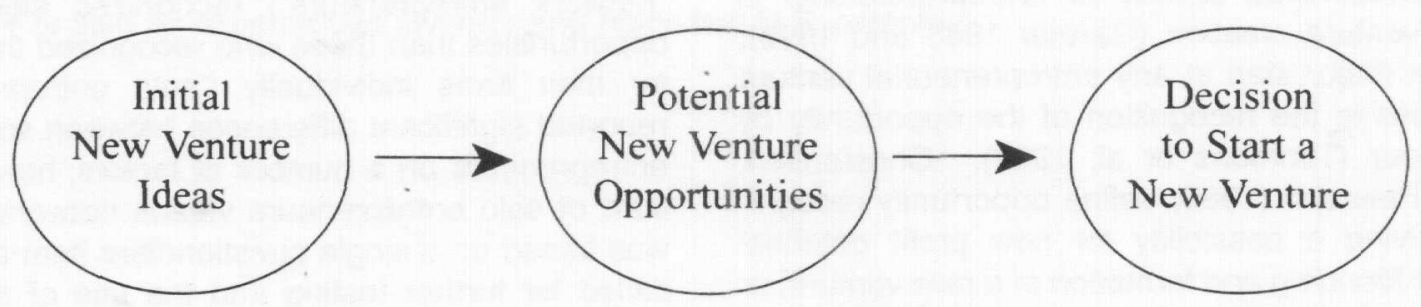

Some people come up with initial new venture ideas. After so additional thought and/or evaluation, they may recognize that their idea are potential new venture opportunities. With even further thought and consideration one may then decide to start a new venture.

\section{Social Networks and Opportunity Recognition}

Clearly, entrepreneurial activity does not occur in a vacuum. Instead, it is embedded in cultural and social contexts, and within webs of human networks that are both social and economic (Reynolds 1992). Because access to information is not uniform across all individuals, it has been proposed that only people at key informational loci within social networks may be able to recognize and take advantage of opportunities (Brittain and Freeman 1980). An entrepreneur's social network ties can expand the boundaries of rationality (Simon 1976) by creating and allowing access to knowledge/information. As the boundary is extended, more new venture ideas and opportunities and potential competitive advantages may be identified/recog- on a number of salient issues. Among the findings, the researchers found that network entrepreneurs identified significantly more opportunities than solo entrepreneurs, and were significantly less likely to go through a formal search. Solo entrepreneurs were more likely to believe that prior employment and "immersion" in an industry are needed to identify opportunities, while network entrepreneurs believed it was easier to see real opportunities after entering a market. These findings hint at some of the important differences between the two types of entrepreneurs. Network entrepreneurs learned of more opportunities than solo entrepreneurs and took advantage of opportunities in which they had no direct experience. They were more likely to take advantage of opportunities in industries that they were not immersed in or did not have personal experience with than were solo entrepreneurs. The authors hypothe- 
sized that network entrepreneurs used their network contacts to access a wider range of information from which feasible opportunities could be recognized. Thus, the size of an entrepreneur's social network will be positively related to the number of new venture ideas identified and new venture opportunities recognized by that entrepreneur; or, more formally:

H1A: The greater the number of social network contacts an entrepreneur uses as idea identification sources, the greater the number of new venture ideas the entrepreneur will identify.

H1B: The greater the number of social network contacts an entrepreneur uses as opportunity recognition sources, the greater the number of new venture opportunities the entrepreneur will recognize.

While network size is important to the opportunity recognition process, the structure of the network may also be important. For most people, their closest friends or relatives ("strong ties"- based on the strength of the relationship) will all know each other, but casual acquaintances ("weak ties") will remain anonymous to an individual's strong ties. Yet, it has been argued that weak ties are more likely to provide unique information (Granovetter 1973) This is due to the fact that an individual who has a group of friends who all know each other will have multiple access points to the information known by each friend-if one friend does not reveal certain information, another one will
Conversely, with weak-tie relationships there is likely to be only one connection between individuals, and the loss of this connection will completely eliminate the possibility of information exchange ever taking place. Burt (1992) argues that it is not the actual relationship (strong or weak) between individuals, but "spaces" between an individual's network contacts that predicts access to unique information. Defining the space between nonredundant contacts as "structural holes," he shows the potential benefits and importance of the holes within a network.

To clarify what structural holes are, Exhibit 2 contrasts a network filled with structural holes with one that is not. To understand the theory behind structural holes, assume an "ideal type" individual can only sustain contact with three other individuals because of the maintenance costs associated with relationships. The exhibit shows that both Entrepreneur $1(E-1)$ and Entrepreneur $2(E-2)$ have direct relations with only three alters, but $\mathrm{E}-1$ has access to more information because of the prevalence of structural holes. (Holes separate E-1's immediate network contacts-they do not have any contact with each other.) The benefits of structural holes are clear: $E-1$ theoretically can receive information from nine individuals, while $E-2$ is limited to only three. In addition, E-2 will be exposed to redundant information. Even if E-2 loses a direct contact, he or she will still have access to the same information, only now some information will be through indirect channels.

While a large network can offer more information, if the network is dense (everyone knows everyone else) the entrepreneur will be exposed to redundant information. The

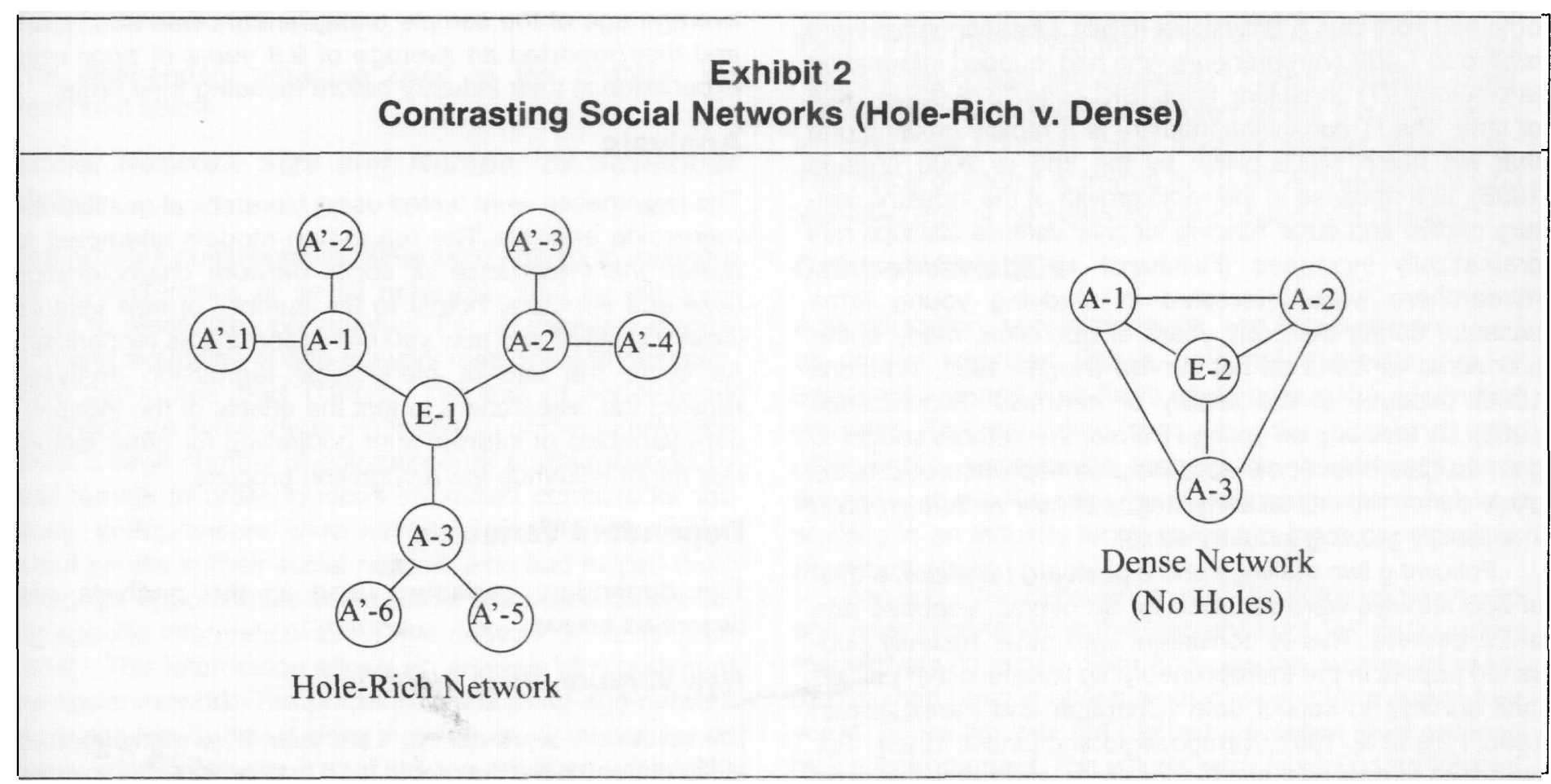


loss of one of the entrepreneur's contacts will not significantly affect access to information. However, when an entrepreneur is connected to a network that contains many structural holes, many of the entrepreneur's network contacts will not know each other. This would suggest that he or she will have access to a much more expansive and diverse amount of knowledge which can give the entrepreneur a competitive advantage in terms of recognizing and taking advantage of opportunities by allowing exposure to more nonredundant information.

In a highly clustered network with few structural holes one is likely to find dense subsets of relations. Such an arrangement usually indicates a small network where every individual is connected directly to every other individual within the network.. In contrast, a hole-rich network allows for indirect and sparse chains that can access wider ranges of information (Mayhew and Levinger 1976; Wellman 1993). This leads to the following two research hypotheses:

H2A:The number of new venture ideas identified by entrepreneurs will be positively related to the number of structural holes in their networks.

H2B:The number of new venture opportunities recognized by entrepreneurs will be positively related to the number of structural holes in their networks.

\section{Research Method}

All data were collected as part of a six-page mail survey questionnaire. The sampling frame for the study was obtained from Dun \& Bradstreet (D\&B). Questionnaires were mailed to 1,402 entrepreneurs who had founded information technology (IT) consulting firms (SIC code 7379-02) in 1994 or later. The IT consulting industry is a rapidly growing one that will reach $\$ 63.6$ billion by the end of 2000 (Zelade 1996), and because of the rapid growth of the industry, venture capital and other funding for new venture startups has dramatically increased (Reinhardt 1998). Further, the researchers were interested in studying young firms because during the early years of operation, many entrepreneurial ventures do not survive (Hogan 1991; Timmons 1986) because of the liability of newness (Stinchcombe 1965). By focusing on young IT firms, the authors sought to gain insights about how successful entrepreneurship takes place during the critical early stages of new venture creation in a rapidly growing industry sector.

Following two mailings and a postcard reminder, a total of 308 surveys were returned for an overall response rate of 22 percent. This is consistent with other recently published papers in the entrepreneurship literature that utilized mail surveys to collect data (Chaganti and Parasuraman 1996; Hills et al. 1997; Karagozoglu and Lindell 1998). For purposes of analysis, two respondents who did not provide key responses to the survey were deleted. Since the independence, risks, and actions taken by those who launch new ventures may differ from franchisees, three franchisees were removed. The remaining 303 respondents were considered "entrepreneurs" for this study. The researchers tested whether there was a difference between respondents and nonrespondents using $t$-tests between mean annual firm revenues, mean numbers of employees, and firm age. Based on these criteria, there were no significant differences between the two groups.

On the first page of the questionnaire, the study entrepreneurs were provided with a model of opportunity recognition that distinguished new venture ideas from new venture opportunities (Singh 2000; Singh et al.1999). Based on the responses to three validity check questions, most entrepreneurs clearly understood and agreed with the model. Less than 8 percent (24) of the respondents reported that they disagreed with the model, and another 23 entrepreneurs were not sure of the model's validity, or answered one of the validity check questions inconsistently with the model. or purposes of analysis, these 47 entrepreneurs were removed because the researchers could not assume that they distinguished between ideas and opportunities. The measurement technique demanded that respondents understand and agree with this distinction. The final respondent sample of entrepreneurs used in this study was 256 , which represented an 18.3 percent useable response rate ( $84.5 \%$ of the mail survey respondents). The mean annual firm revenues and number of employees were $\$ 1,150,145$ and 10.8 , respectively. Respondents were located in 41 states and the District of Columbia. The average age of the sample entrepreneurs was 38.7 years and they reported an average of 9.8 years of prior work experience in their industry before founding their firms.

\section{Analysis}

The hypotheses were tested using hierarchical multivariate regression analysis. The regression models attempted to isolate the importance of social network characteristics (size and structural holes) to the number of new venture ideas identified and new venture opportunities recognized. As such, the use of hierarchical regression analyses allowed the researchers to test the effects of the independent variables of interest after controlling for other factors that might influence the recognition process.

\section{Dependent Variables}

The dependent variables used in the analysis are described below:

\section{New Venture Ideas Identified}

Entrepreneurs were asked: "Last year, how many venture ideas did you have that could lead to potential new venture 
opportunities?" Entrepreneurs could choose a number from 0 to 7 , or they could select " $8-10$ " or " $11+$." The choice of "8-10" was coded as a " 9 " and "11+" as a "12." The selection of " 9 " was obvious, and the choice of " 12 " for the "11+" response was a conservative estimate of the number of new venture ideas recognized. The measure ranged from 0 to 12. Square root transforms of entrepreneurs responses were used in the analysis.

\section{New Venture Opportunities Recognized}

Entrepreneurs were asked: "Based on the ideas you had last year, how many potential new venture opportunities did you recognize?" Again, entrepreneurs could choose a number from 0 to 7 , or they could select "8-10" or " $11+$." The measure was coded as described in the previous sec tion and square root transforms of entrepreneurs' responses were also used in the analysis.

Two points concerning the dependent variable mea sures warrant further discussion. First, entrepreneurs were asked to consider the ideas and opportunities that they had identified/recognized over the last year to make the time frame consistent for all entrepreneurs. Second, the square root transform was used to linearize the relation ships between the independent and dependent variables, and to achieve a normal distribution of the residuals (Agresti and Finlay 1986; Cohen and Cohen 1975; Norusis 1991). The square root transform was chosen after reviewing the frequency histogram of the regression standardized residuals because it best normalized the regression standardized residuals (Cohen and Cohen 1975).

\section{Independent Variables}

The independent variables used in the analysis are described below:

\section{Social Network Size and Number of Structural Holes}

Ego-network questionnaire items were utilized to measure the characteristics of social networks used by entrepreneurs to recognize opportunities. For an excellent discussion and examples of ego-network methods and questionnaire items, see Burt (1984). The use of ego-network questionnaire items made it possible to gather information about a large number of entrepreneurs' social networks by mail survey. In order to focus on salient contacts for this study, entrepreneurs were asked to provide information about people in their social network who had helped them recognize opportunities using Burt's procedure for gathering specific information about five network contacts (Burt 1984). This information allows an analysis of a portion of the social network. The primary benefit of an ego-network questionnaire is that it does not require a researcher to gather information about all of the ties within an individual's network domain; yet, it provides a reasonable representation of an individual's overall network (Burt 1984; Marsden 1987; Wellman 1993)

The total number of contacts identified as individuals who the entrepreneur had relied on to recognize opportunities (network size) was directly measured on the questionnaire. The questionnaire is worded so that the number of contacts variable is the total number of contacts that helped the entrepreneur recognize opportunities since firm founding (including the opportunity for their firm). Thus, it does not match the one-year time frame used for the number of ideas and opportunities recognized (except for entrepreneurs whose firms were founded one year earlier). Nevertheless, this time difference is not likely to significantly affect these relationships because of the stability of social networks (Davern 1997). The total number of contacts variable is a representation of the size of an entrepreneur's social network and the propensity to use the network to recognize opportunities (i.e., how "networked" an entrepreneur is). An individual who utilized eight contacts to recognize opportunities is more networked than an individual who used only one. Although there is a dynamic component to social networks as individual network contacts change over time, the overall size and composition (types of individuals, i.e., race, gender, age, etc.) of the network remains fairly stable (Davern 1997). In this study, this is partially supported by the nonsignificant correlation between firm age and number of contacts.

The number of structural holes in the entrepreneur's network was calculated by examining the relationships between the entrepreneurs' five identified contacts. For those respondents with two or more contacts (since there needs to be at least two contacts to have a structural hole), the number of instances was noted where the respondent indicated that contacts knew another contact "Not at All." The range of values is from 0 to 10 . All entrepreneurs who identified one or no contacts were coded with 0 holes.

\section{Control Variables}

Age, education, prior experience, and firm age were used as control variables. These personal characteristics of entrepreneurs and their firms could impact the dependent variables. Age, education level, and prior experience may offer some opportunity recognition advantages and, according to the "Corridor Principle," being in business and working in an industry tends to lead to more opportunities (Ronstadt 1988).

Age and Prior Experience were the entrepreneur's age and prior experience in the industry prior to firm founding respectively (in years). Firm Age was the number of years the firm had been in operation and ranged from one to four years. Education was the highest education level attained by the entrepreneur. The values were based on an interval 
scale of education level, from $1=$ Some High School to 6=Graduate Degree.

\section{Findings}

Exhibit 3 summarizes the descriptive statistics (means, standard deviations, and correlations) for all variables used in the analyses.

To test Hypotheses $1 \mathrm{~A}$ and $2 \mathrm{~A}$ the square root trans- ber of structural holes was also significant and positive $(b=.115, p<.05)$. These results provide support for Hypothesis 2A. Overall, the results suggest that after controlling for other potentially important factors, the size of the entrepreneur's social network and the number of structural holes in the network are significantly and positively related to the number of new venture ideas identified.

To test Hypotheses $1 \mathrm{~B}$ and $2 \mathrm{~B}$, the square root trans-

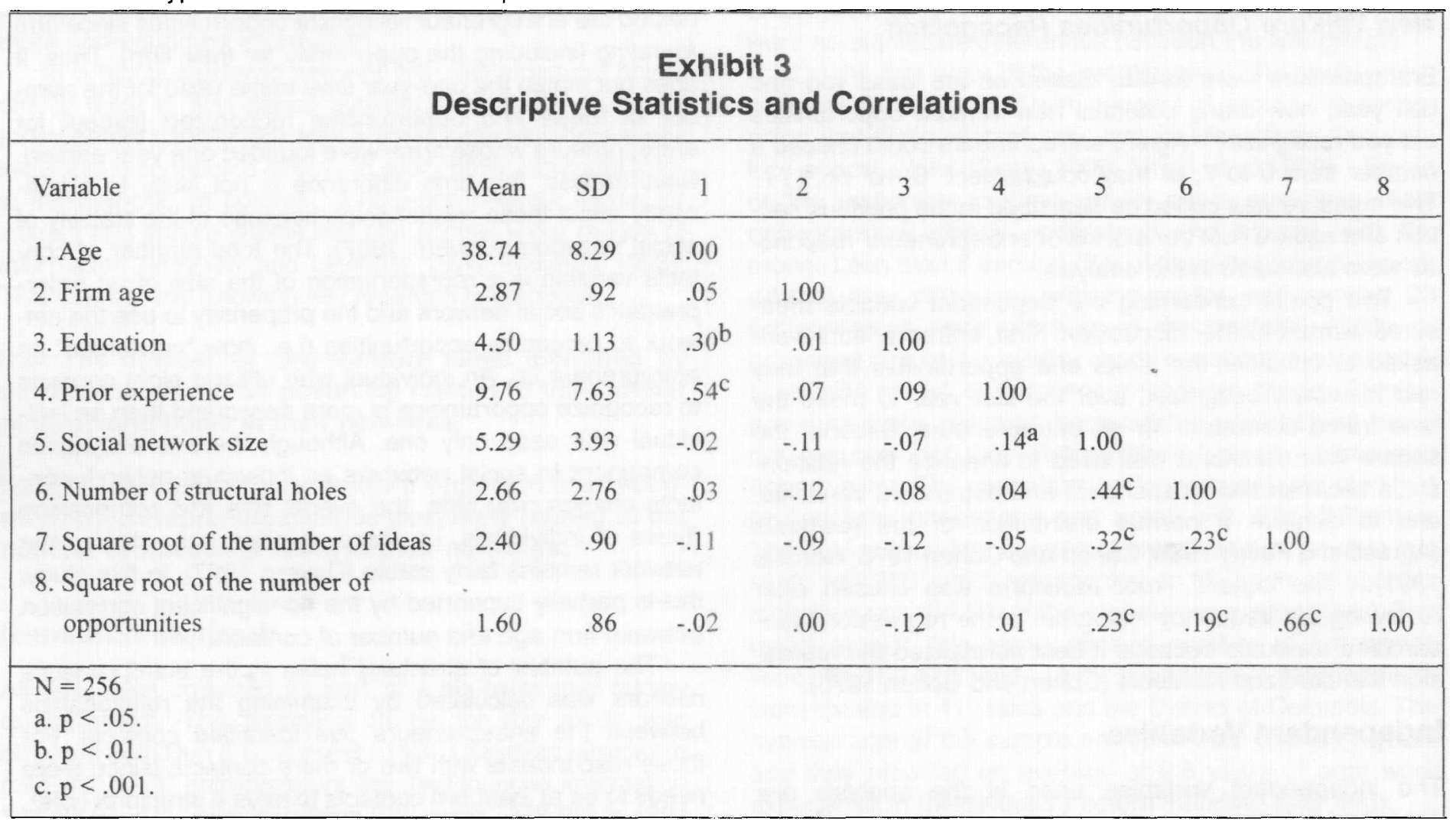

form of the number of new venture ideas entrepreneurs identified in the last year was first regressed on the four control variables (age, education, years of prior experience, and firm age) and then on the two independent variables. Exhibit 4 summarizes statistical results for tests of the effects of various independent variables on the numbers of new venture ideas identified.

The results provide strong support for Hypothesis $1 \mathrm{~A}$ as social network size (total number of contacts identified) was positively related to the number of ideas identified (see Model 2 in Exhibit 4). Network size significantly improved the explanatory power of the regression equation over just the control variables $(p<.001)$. Model 2 resulted in an adjusted $R^{2}$ of $.103(F=6.769, p<.001)$. The standardized regression coefficient for network size was positive and significant $(\beta=.311, p<.001)$.

Model 3 in Exhibit 4 added the number of structural holes used to identify ideas to the regression equation. Model 3 explained almost 1 percent more variance than Model 2. The standardized regression coefficient for num- form of the number of opportunities entrepreneurs recognized in the last year was regressed on the four control variables and then on the independent variables following the same procedure described above. Exhibit 5 summarizes the statistical results.

Again, the results provide strong support for Hypothesis $1 \mathrm{~B}$ as social network size (total number of contacts identified) was positively related to the number of opportunities recognized (see Model 2 in Exhibit 5). Network size significantly improved the explanatory power of the regression equation over just the control variables $(p<.001)$. Model 2 resulted in an adjusted $\mathrm{R}^{2}$ of $.046(F=3.425, p<.01)$. The standardized regression coefficient for network size was positive and significant $(\beta=.231, p<.001)$.

Model 3 in Exhibit 5 added the number of structural holes used to recognize opportunities to the regression equation. Model 3 explained more variance than Model 2, although it was not a statistically significant improvement. The standardized regression coefficient for number of 


\section{Exhibit 4}

\section{Results of Regression Analyses for the Square Root of the Number of New Venture Ideas Identified by Respondents in the Last Year}

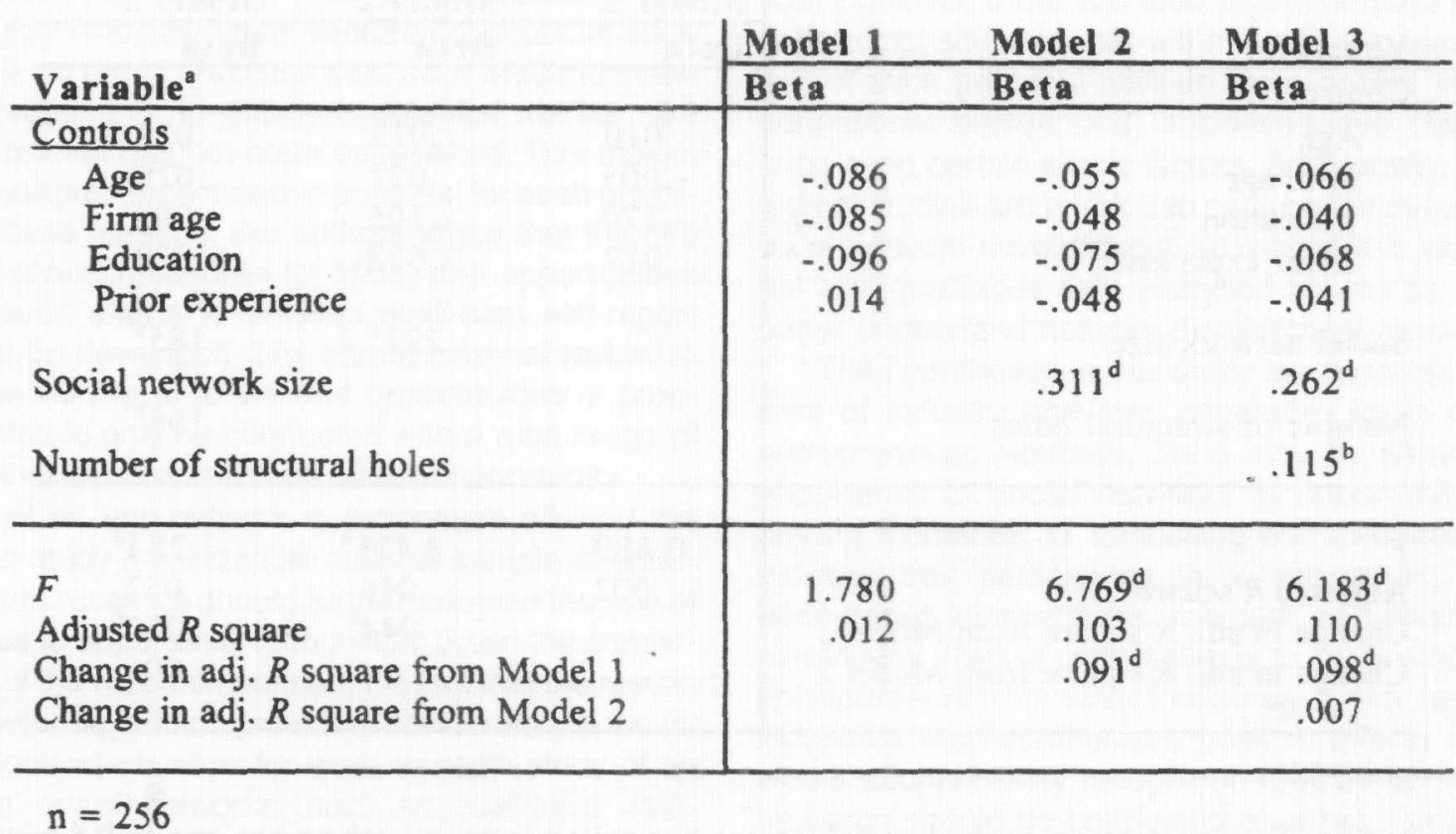

a. Significance tests on control variables are two-tailed tests, all others are one-tailed tests.

b. $\mathrm{p}<.05$.

c. $\mathrm{p}<.01$.

d. $p<.001$.

structural holes was positive but only marginally significant $(\beta=.108, p<.10)$. Thus, these results provide weak support for Hypothesis $2 \mathrm{~B}$.

Similar to the findings above, the results suggest that after controlling for other potentially important factors, the size of the social network is significantly and positively related to the number of new venture opportunities recognized.

\section{Discussion}

This article reports on the investigation of the importance of social networks to the opportunity recognition process. Three of the four research hypotheses were supported by the results of this study and one was marginally supported. These results provide empirical evidence that entrepreneurs recognize the two phases of the opportunity recognition process (idea identification and opportunity recognition), and that specific elements of an entrepreneur's social network play a role in these two phases of the opportunity recognition process. The size of the network is an indicator of the total body of knowledge that an entrepreneur has access to-the larger the network the more information. This broader base of information can lead the entrepreneur to the identification of more ideas as well as the recognition of more opportunities. But this article goes beyond just network size and finds support for the importance of structural holes in the network. Based on the results, Burt's (1992) theory of the importance of holes within the network is supported with respect to new venture idea identification, but there was only marginal support for the importance of structural holes to opportunity recognition. This again supports the concept that opportunity recognition is a process and that idea identification is a separate construct within the process.

Being the first study to examine the role of structural holes to the opportunity recognition process, the researchers were encouraged by the results. However, 


\section{Exhibit 5}

Results of Regression Analyses for the Square Root of the Number of New Venture Opportunities Recognized by Respondents in the Last Year

\begin{tabular}{|c|c|c|c|}
\hline \multirow[b]{2}{*}{ Variable $^{a}$} & Model 1 & Model 2 & Model 3 \\
\hline & Beta & Beta & Beta \\
\hline \multicolumn{4}{|l|}{ Controls } \\
\hline Age & .010 & .033 & .022 \\
\hline Firm age & -.005 & .022 & $.029^{c}$ \\
\hline Education & -.120 & -.105 & -.098 \\
\hline Prior experience & .017 & -.028 & -.022 \\
\hline Social network size & & $.231^{\mathrm{e}}$ & $.185^{\mathrm{d}}$ \\
\hline Number of structural holes & & & $.108^{b}$ \\
\hline$F$ & 0.880 & $3.425^{\mathrm{d}}$ & $3.284^{d}$ \\
\hline Adjusted $R$ square & .002 & .046 & .052 \\
\hline Change in adj. $R$ square from Model 1 & & $.044^{e}$ & $.050^{\mathrm{e}}$ \\
\hline Change in adj. $R$ square from Model 2 & & & .006 \\
\hline
\end{tabular}

a. Significance tests on control variables are two-tailed tests, all others are one-tailed tests.

b. $\mathrm{p}<.10$.

c. $\mathrm{p}<.05$.

d. $\mathrm{p}<.01$.

e. $\mathrm{p}<.001$.

while the results were significant, they expected more of the variance to be explained by their independent variables. The explanation for the low variance was related to the inherently conservative nature of their research method. While an ego-network questionnaire provides a reasonable representation of an individual's overall network (Burt 1984 and 1985; Marsden 1987 and 1990; Wellman 1993), there are limitations to its use. There is a bias toward strong-tie contacts because it is easier for respondents to remember the names and roles of strong tie contacts than weak ties (Burt 1986; Haung and Tausig 1990; Marsden 1987). In addition, the maximum number of holes in this study was 10 , but given that there tends to be a bias toward strong ties when using an ego-network survey, the researchers would expect that there would be fewer structural holes within the network of identified contacts than other parts of the respondents' networks. Thus, the results of this study are conservative with respect to the importance of structural holes to idea identification and opportunity recognition. This may be because only examining five contacts is not sufficient to fully assess the importance of structural holes to the opportunity recognition process.

Another limitation of the study is that single self-report questionnaire items were used to measure each of the dependent variables "ideas identified" and "opportunities recognized." Some researchers may argue for objective (outside) assessment of whether the entrepreneurs have truly identified an idea or recognized an opportunity. In a forthcoming paper, Singh (in press) discusses the primary problem with current conceptions of opportunity. Specifically, that other constructs and confounding variables are intertwined with the opportunity construct (e.g., success, profitability, resources controlled). For opportunity to exist and be a construct capable of examination, it must be identifiable before the venture is founded and success is gained. Researchers cannot rely on 20/20 hindsight

54 NEW ENGLAND JOURNAL OF ENTREPRENEURSHIP 
to discuss entrepreneurial opportunities post hoc. The use of retrospective case studies or archival data for empirical studies of entrepreneurship over time is problematic because bias can result when outcomes are known. Thus, researchers should not limit study to what they perceive to be "good" opportunities because the entrepreneur's perceived reality of what constitutes an opportunity may be difficult to assess (Christensen 1989), particularly with respect to highly innovative new venture concepts. In such cases, there is no direct historical data from which to make financial projections or to estimate potential market size because the market has not been established. This makes it difficult to evaluate the economic potential for such opportunities. For these reasons, the authors argue that the use of single self-report measures for ideas and opportunities is valid; however, efforts to develop multi-item self-report scales should be developed. The use of external review to determine the validity of ideas and opportunities is problematic and should only be conducted with a wide range of latitude about what constitutes an idea or opportunity.

The use of an ego-network questionnaire allowed the researchers to study a substantial national sample of entrepreneurs. Future research should further examine the role of structural holes to opportunity recognition. Given the conservative nature of the research method, the fact that the results of this study were significant provide a contribution to the literature. Methods which allow for more in-depth study of an entrepreneurs' social networks, such as qualitative datagathering interviews, may lead to more significant findings (and more variance explained) related to the importance of the structural holes to opportunity recognition.

For entrepreneurs and those interested in more effectively identifying opportunities, the findings of this study strongly suggest that social networks are critical during the opportunity recognition process. The use of social contacts during the idea identification and opportunity recognition phases of new venture creation allows an entrepreneur to obtain external validity for the quality of the idea/opportunity by virtue of the input and knowledge of others. Additionally, using social network contacts in the opportunity recognition process may also help reduce the liability of newness. By actively engaging in exchange behaviors with relevant social contacts (potential clients, friends, business contacts, family members), entrepreneurs may be better equipped to obtain resources such as financial backing, psychological support, physical goods, and business information to facilitate their ventures' survival (Hansen and Allen 1992).

\section{Future Research}

The largest research need is for more complete analyses and data collection of entrepreneurs' full social networks. The ego-network survey method provides only a representative picture of entrepreneurs' social networks. More inten- sive analyses of social networks are now required to better understand the link between social network contacts and opportunity recognition. Research is also needed to determine how successful entrepreneurs develop their networks. Certain personal characteristics of entrepreneurs may improve opportunity recognition by improving the ability to have and/or build networks that are conducive to recognition. However, there are also characteristics of an individual's social situation that will make the successful application of such personal abilities more or less likely, such as educational background, socioeconomic class, and perhaps even certain ethnic factors. Additionally, further longitudinal studies are needed to capture the dynamic processes of network development. To extend this work, longitudinal and qualitative data analyses should be performed to better understand network development processes.

The hypotheses in this study are theoretically independent of industry and may generalize to all profit-seeking entrepreneurs. However, there may be differences in the importance of social networks to opportunity recognition among industries. IT consulting entrepreneurs exist in an industry that participates in a "networking" culture that encourages joint ventures, mergers, and alliances in the IT community. Thus, a critical step is to study other samples of entrepreneurs from other industries. It may be that in other industries the hypothesized positive affects of social networks to opportunity recognition may be enhanced. Future research should be conducted on other samples of entrepreneurs in other industries, as well as from other sampling frames (i.e., non-D\&B entrepreneurs) to test the overall generalizability of the findings.

All of the firms in this study have both survived and achieved at least a modest level of success (all firms generated at least $\$ 100,000$ in annual revenues). But what of the firms that failed? It is possible that there were significant differences in the use of social network contacts during the opportunity recognition process. It is also possible that the use of social networks during the opportunity recognition phase of new venture creation can reduce the liability of newness faced by newly founded firms (Stinchcombe 1965). This may be a fruitful area for future research.

Finally, future research should also study the effects of social networks on the opportunity recognition processes of women and minority entrepreneurs. The sample in this study was mostly white male entrepreneurs. Research has shown that women and minorities develop different types of networks than their white male counterparts (Ibarra 1992 and 1993), and these differences can affect social and political attitudes (Bienenstock et al.1990). By oversampling women and minority entrepreneurs, we may find that social network variables have more significant impacts on opportunity recognition for minority and female entrepreneurs. Ultimately, understanding differential patterns in the 
social networks of entrepreneurs from demographically different backgrounds may yield useful information about disparities in revenues between their firms.

\section{Conclusions}

Several issues of critical importance to understanding opportunity recognition have been explored in this article. The important role played by contacts within an entrepre- neur's social network to idea identification and subsequent opportunity recognition was empirically supported. More specifically, network size and the number of structural holes in the social network were found to be significantly and positively related to idea identification and opportunity recognition. Although there remains a gap in the literature on opportunity recognition, this article helps to shed light on the opportunity recognition process. The findings have important

implications for both practitioners and researchers.

\section{References}

Agresti, A., and B. Finlay, Statistical Methods for the Social Sciences (2nd edition). San Francisco: Dellen Publishing Company (1986).

Aldrich, H. E., B. Rosen, and W. Woodward. "The Impact of Social Networks on Business Foundings and Profit: A Longitudinal Study," Frontiers in Entrepreneurship Research 7 (1987), pp. 154-168.

Barnes, J., Social Networks. Philippines: Addison-Wesley (1972).

Bienenstock, E., P. Bonacich, and M. Oliver, "The Effect of Network Density and Homogeneity on Attitude Polarization," Social Networks 12 (1990), pp. 153-172.

Brittain J. W., and J. H. Freeman, "Organizational Proliferation and Density Dependent Selection." In The Organizational Life Cycle, eds. J. R. Kimberly and R.H. Miles. San Francisco: Jossey-Bass (1980), pp. 291-338.

Burt, R. S., "Network Items and the General Social Survey," Social Networks 6 (1984), pp. 293-339.

Burt, R. S., "General Social Survey Items," Connections 8 (1985), pp. 119-122.

Burt, R. S., "A Cautionary Note," Social Networks 8 (1986), pp. 205-211.

Burt, R. S., Structural Holes: The Social Structure of Competition. Cambridge, MA: Harvard University Press (1992).

Bygrave, B., The Portable MBA in Entrepreneurship. New York: John Wiley \& Sons (1994).

Chaganti, R., and S. Parasuraman, "A Study of the Impacts of Gender on Business Performance and Management Patterns in Small Businesses," Entrepreneurship Theory \& Practice 21 No. 2 (1996), pp. 73-75.

Christensen, P. S., Strategy: Opportunity Identification and Entrepreneurship. Aarhus University, Institute of Management (1989).

Christensen, P. S., O. O. Madsen, and R. Peterson, R., Opportunity Identification: The Contribution of Entrepreneurship to Strategic Management. Denmark: Aarhus University Institute of Management (1989).

Christensen, P. S., and R. Peterson, "Opportunity Identification: Mapping the Sources of New Venture Ideas" (paper presented at the 10th Annual Babson Entrepreneurship Research Conference, April 1990). Denmark: Aarhus University Institute of Management.

Cohen, J., and P. Cohen, Applied Multiple Regression/Correlation Analysis for the Behavioral Sciences. Hillsdale, NJ: Lawrence Erlbaum Associates, Publishers (1975). 
Davern, M., "Social Networks and Economic Sociology: A Proposed Research Agenda for a more Complete Social Science," American Journal of Economics \& Sociology 56 No. 3 (1997), pp. 287-302.

W. B. Gartner, "A Conceptual Framework for Describing the Phenomenon of New Venture Creation," Academy of Management Review 10 no. 4 (1985), pp. 696-706.

Gartner, W. B., "What Are We Talking About When We Talk About Entrepreneurship?" Journal of Business Venturing 5 (1990), pp. 15-28.

Granovetter, M., "The Strength of Weak Ties," American Journal of Sociology 78 No. 6 (1973), pp. 1360-1380.

Hansen, E. L., "Entrepreneurial Networks and New Organization Growth," Entrepreneurship Theory and Practice 19 No. 4 (1995), pp. 7-19.

Hansen, E. L., and K. R. Allen, "The Creation Corridor: Environmental Load and Pre-organization InformationProcessing Ability," Entrepreneurship Theory and Practice 17 No. 1 (1992), pp. 57-66.

Haung, G., and M. Tausig, "Network Range in Personal Networks," Social Networks 12 (1990), pp. 261-268.

Hills, G. E., "Opportunity Recognition by Successful Entrepreneurs: A Pilot Study." Frontiers of Entrepreneurship Research 15 (1995), pp. 105-117.

Hills, G. E., G. T. Lumpkin, and R. P. Singh, "Opportunity Recognition: Perceptions and Behaviors of Entrepreneurs," Frontiers of Entrepreneurship Research 17 (1997), pp. 168-182.

Hogan, B., "How to Hatch New Businesses." D\&B Reports, 39(4) (1991), pp. 54-55.

Ibarra, H., "Homophily and Differential Returns: Sex Differences in Network Structure and Access in an Advertising Firm," Administrative Science Quarterly 37 (1992), pp. 422-447.

Ibarra, H., "Personal Networks of Women and Minorities in Management: A Conceptual Framework," Academy of Management Review 18 (1993), pp. 56-87.

Johannisson, B., "Economics of Overview-Guiding the External Growth of Small Firms," International Small Business Journal 9 (1990), pp. 32-44.

Karagozoglu, N., and M. Lindell, "Internationalization of Small and Medium-sized Technology-based Firms: An Exploratory Study," Journal of Small Business Management 36 No. 1 (1998), pp. 44-59.

Koller, R. H.,"On the Source of Entrepreneurial Ideas, Frontiers of Entrepreneurship Research 8 (1988), pp. 194-207.

Marsden, P., "Core Discussion Networks of Americans," American Sociological Review 52 (1987), pp. 122-131.

Marsden, P., "Network Data and Measurement," Annual Review of Sociology 16 (1990), pp. 435463.

Mayhew, B. H., and R. L. Levinger, "Size and the Density of Interaction in Human Aggregates," American Journal of Sociology 82 (1976), pp. 86-110.

Mitchell, J., Social Networks in Urban Situations, Manchester: Manchester University Press (1969).

Norusis, M. J., The SPSS Guide to Data Analysis for SPSS/PC+ (2nd edition). Chicago, IL: SPSS, Inc (1991).

Pool, I and M. Kochen, "Contacts and Influence," Social Networks 1 (1978), pp. 5-51.

Reinhardt, A., "Risks and Rewards: No Slacking in Silicon Valley," Business Week, August 31 (1998), pp. $88-92$. 
Reynolds, P. D., "Sociology and Entrepreneurship: Concepts and Contributions," Entrepreneurship Theory and Practice 16 (1992), pp. 47-70.

Ronstadt, R. "The Corridor Principle," Journal of Business Venturing 3 (1988), pp. 31-40.

Simon, H. A., Administrative Behavior, 3rd edition. New York: Free Press (1976).

Singh, R. P., Entrepreneurial Opportunity Recognition through Social Networks. New York: Garland Publishing (2000).

Singh, R. P., "A Comment on Developing the Field of Entrepreneurship through the Study of Opportunity Recognition and Exploitation," Academy of Management Review (In Press).

Singh, R. P., G. E. Hills, and G. T. Lumpkin, "New Venture Ideas and Entrepreneurial Opportunities: Understanding the Process of Opportunity Recognition." 1999 United States Association for Small Business and Entrepreneurship (USASBE) Conference, 13th annual national conference.

Stinchcombe, A L., "Social Structure in Organizations." In Handbook of Organizations: ed. J.G. March . Chicago: Rand McNally (1965), (pp. 142-193).

Timmons, J. A., "Growing up Big." In The Art and Science of Entrepreneurship. ed. D.L. Sexton and R.W. Smilor. Cambridge, MA: Ballinger (1986), pp. 223-239.

Timmons, J. A., New Business Opportunities: Getting to the.Right Place at the Right Time. Acton, MA: Brick House Publishing Co. (1990).

Timmons, J. A, New Venture Creation: Entrepreneurship for the 21st Century. (4th ed.), Burr Ridge, IL: Irwin (1994).

Timmons, J. A., D. F. Muzyka, H. H. Stevenson, and W. D. Bygrave, "Opportunity Recognition: The Core of Entrepreneurship," Frontiers of Entrepreneurship Research 7 (1987), pp. 109-123.

Wellman, B., "An Egocentric Network Tale," Social Networks 15 (1993), pp. 423-436.

Zhao, L., and J. D. Aram, "Networking and Growth of Young Technology-Intensive Ventures in China," Journal of Business Venturing, 10 (1995), pp. 349-370.

Zelade, R., "Global Consulting Grows," International Business 9(8) (1996), p. 6.

\section{Acknowledgement}

Portions of this article were presented at the 1999 Babson College-Kauffman Foundation Entrepreneurship Research Conference.

\section{MEjE}

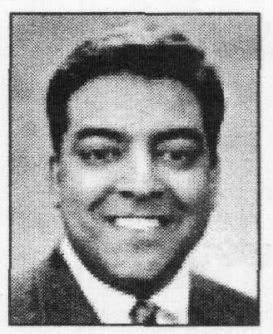

Robert P. Singh is an assistant professor of management at the University of the Pacific in Stockton, California. He completed his Ph.D. at the University of IIlinois at Chicago, his MBA at Illinois Institute of Technology, and his undergraduate degree at the University of Virginia in mechanical engineering. Dr. Singh's papers have appeared in the Best Paper Proceedings Academy of Management Meeting, Frontiers of Entrepreneurship Research, Research at the Marketing/ Entrepreneurship Interface, Human Resource Management Journal, and Human Resource Planning. His current research focuses on entrepreneurial opportunity recognition, social networks of entrepreneurs, and Internet ventures. 


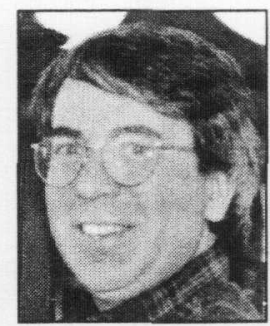

Ralph C. Hybels is the president of Leadership in Medicine, Inc., a management consulting firm based in Vermont. He earned his BA from University of Massachusetts, Amherst, and his MS and Ph.D. from Cornell University, New York State School of Industrial and Labor Relations. His papers have been published in the Best Papers Proceedings Academy of Management Meeting and Administrative Science Quarterly. Dr. Hybels has also published chapters in Organizations in Industry, Networks and Organizations, and Organizational Issues in High Technology Management.

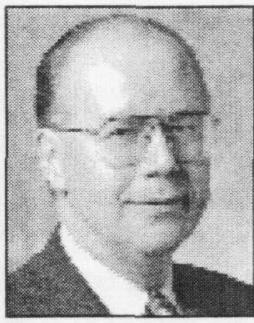

Gerald E. Hills is holder of the Coleman/Denton Thorne Chair in Entrepreneurship (established by the Coleman Foundation), executive director of the Institute for Entrepreneurial Studies, and professor of marketing at the University of Illinois at Chicago. His MBA and doctorate are from Indiana University. Dr. Hills has written and edited 10 books and written more than 75 refereed articles. He is past-president of the International Council for Small Business and cofounder and first president of the U.S. Association for Small Business and Entrepreneurship (USASBE). 